\title{
A Patient with Heart Failure and Sleep-disordered Breathing Who Presented with Marked Reverse Remodeling by Continuous Positive Airway Pressure Therapy
}

Taishi Fukushima ${ }^{1}$, Kenichiro Yasuda ${ }^{1}$, Kazuo Eguchi ${ }^{2}$, Masahiko Fujino ${ }^{3}$ and Haruo Kamiya ${ }^{1}$

\begin{abstract}
:
A 49-year-old Japanese man with worsening dyspnea was admitted with the diagnosis of new-onset heart failure (HF). His HF symptoms improved with standard treatment, but his left ventricular ejection fraction (LVEF) $21 \%$ remained unchanged. After he was discharged, he was diagnosed with severe sleep-disordered breathing (SDB). Continuous positive airway pressure (CPAP) therapy was introduced. Seven months later, his cardiac function had greatly improved (LVEF 50\%). We report this case of a HF patient with SDB whose cardiac function greatly improved by CPAP therapy, and we discuss the pathophysiologic mechanisms of successful cardiac "reverse remodeling" in this case.
\end{abstract}

Key words: heart failure, sleep-disordered breathing, positive airway pressure, reverse remodeling

(Intern Med 56: 2289-2294, 2017)

(DOI: 10.2169/internalmedicine.8525-16)

\section{Introduction}

Sleep-disordered breathing (SDB) including obstructive and central sleep apnea (OSA and CSA) has been observed in from $24-61 \%$ of patients with heart failure (1-3). The use of continuous positive airway pressure (CPAP) therapy has been reported to reduce the risk of death and hospitalization in heart failure patients with OSA (4). Moreover, CPAP use ameliorates the cardiac function through mainly decreasing afterload in heart failure patients with $\operatorname{OSA}(5,6)$. However, there are considerable variations among the heart failure patients with OSA regarding the degree of improvement in cardiac function as represented by the left ventricular ejection fraction (LVEF), from only a few percent to more than $20 \%$ after CPAP use (7-9). It is not yet known which types of heart failure patients respond well to CPAP (10-12). We herein present the case of a patient with heart failure and SDB whose cardiac function dramatically improved after CPAP therapy was initiated.

\section{Case Report}

A 49-year-old Japanese man with heart failure was referred to our hospital in April 2015. He had been complaining of exertional dyspnea for 1 month and resting dyspnea for 1 week. He had experienced a substantial weight gain over the past 5 years. He was diagnosed to have hypertension 4 years earlier, but had not been treated for it. He had smoked a half-a-pack of cigarettes daily starting 20 years earlier, and drank alcohol occasionally. He had no known family history of heart failure.

On admission, the patient's body height and weight were $170 \mathrm{~cm}$ and $94 \mathrm{~kg}$, and his body mass index was $32.5 \mathrm{~kg} /$ $\mathrm{m}^{2}$. His blood pressure was $142 / 99 \mathrm{mmHg}$; pulse rate, 115 bpm; and the oxygen saturation, $99 \%$ with $2 \mathrm{~L} / \mathrm{min}$ via nasal cannula. Auscultation revealed no S3, S4, or audible murmur, and minimal bibasilar coarse crackles were heard. Jugular venous distension and pitting edema in both lower extremities were observed. Blood tests showed a white blood cell count of $10,700 / \mu \mathrm{L}$, serum creatinine of $1.21 \mathrm{mg} /$

${ }^{1}$ Department of Cardiology, Japanese Red Cross Nagoya First Hospital, Japan, ${ }^{2}$ Division of Cardiovascular Medicine, Department of Medicine, Jichi Medical University School of Medicine, Japan and ${ }^{3}$ Department of Pathology, Japanese Red Cross Nagoya First Hospital, Japan Received: November 9, 2016; Accepted: January 11, 2017; Advance Publication by J-STAGE: August 10, 2017 Correspondence to Dr. Taishi Fukushima, m09090tf@jichi.ac.jp 
Table 1. Laboratory Findings on Admission for the Heart Failure Patient.

\begin{tabular}{|c|c|c|c|c|c|c|}
\hline WBC & $10,700 / \mu \mathrm{L}$ & BNP & $599 \mathrm{pg} / \mathrm{mL}$ & Plasma epinephrine & $32 \mathrm{pg} / \mathrm{mL}$ & $(<100)^{*}$ \\
\hline Neut & $82.5 \%$ & CRP & $0.52 \mathrm{mg} / \mathrm{dL}$ & Plasma norepinephrine & $1,441 \mathrm{pg} / \mathrm{mL}$ & $(100-450)^{*}$ \\
\hline Lymph & $10.9 \%$ & $\mathrm{TP}$ & $5.7 \mathrm{~g} / \mathrm{dL}$ & urinary normetanephrine/creatinine & $0.46 \mu \mathrm{g} / \mathrm{mgCre}$ & \\
\hline Mon & $5.4 \%$ & Alb & $3.3 \mathrm{~g} / \mathrm{dL}$ & urinary metanephrine/creatinine & $0.1 \mu \mathrm{g} / \mathrm{mgCre}$ & \\
\hline Eos & $0.8 \%$ & T-Bil & $1.1 \mathrm{mg} / \mathrm{dL}$ & Plasma renin activity & $0.7 \mathrm{ng} / \mathrm{mL} / \mathrm{hr}$ & $(0.2-3.9)^{*}$ \\
\hline $\mathrm{RBC}$ & $520 \times 10^{4} / \mu \mathrm{L}$ & AST & $32 \mathrm{U} / \mathrm{L}$ & Plasma aldosterone concentration & $120 \mathrm{pg} / \mathrm{mL}$ & $(30-159)^{*}$ \\
\hline $\mathrm{Ht}$ & $45 \%$ & ALT & $42 \mathrm{U} / \mathrm{L}$ & Cortisol & $12.2 \mu \mathrm{g} / \mathrm{dL}$ & $(4.0-19.3)^{*}$ \\
\hline $\mathrm{Hb}$ & $14.7 \mathrm{~g} / \mathrm{dL}$ & $\mathrm{CK}$ & $176 \mathrm{U} / \mathrm{L}$ & TSH & $2.051 \mu \mathrm{U} / \mathrm{mL}$ & $(0.35-4.94)^{*}$ \\
\hline \multirow[t]{4}{*}{ Plt } & $23.7 \times 10^{4} / \mu \mathrm{L}$ & BUN & $22 \mathrm{mg} / \mathrm{dL}$ & free $\mathrm{T} 3$ & $2.8 \mathrm{pg} / \mathrm{mL}$ & $(1.71-3.71)^{*}$ \\
\hline & & Cre & $1.21 \mathrm{mg} / \mathrm{dL}$ & free $\mathrm{T} 4$ & $1.18 \mathrm{ng} / \mathrm{dL}$ & $(0.70-1.48)^{*}$ \\
\hline & & $\mathrm{Na}$ & $140 \mathrm{mEq} / \mathrm{L}$ & & & \\
\hline & & K & $4.4 \mathrm{mEq} / \mathrm{L}$ & & & \\
\hline
\end{tabular}

* represent normal ranges

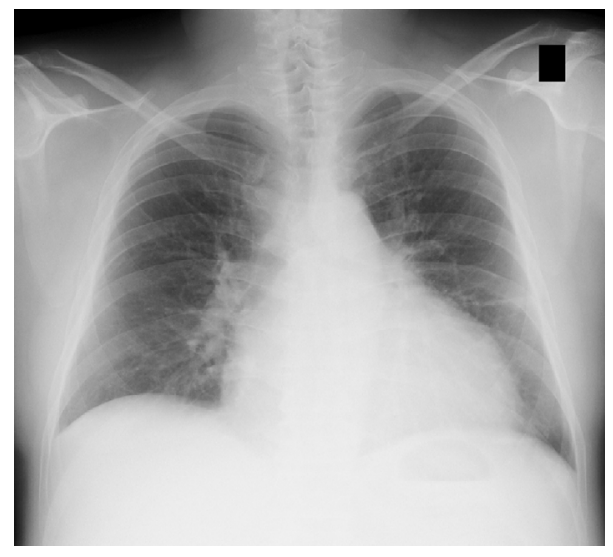

Figure 1. Chest radiograph on admission showed cardiomegaly (CTR 65\%).

$\mathrm{dL}$, and brain natriuretic peptide of $599 \mathrm{pg} / \mathrm{mL}$ (Table 1). The serum norepinephrine concentration was $1,441 \mathrm{pg} / \mathrm{mL}$ (normal range: $100-450 \mathrm{pg} / \mathrm{mL}$ ), but the results of other endocrine tests were normal. A chest radiograph showed cardiomegaly (cardiothoracic ratio [CTR] 65\%: Fig. 1) with congestion. A 12-lead electrocardiogram demonstrated sinus tachycardia, left atrial overload, and clockwise rotation (Fig. 2). Echocardiography on admission showed diffusely reduced left ventricular (LV) contraction: LVEF with modified Simpson's method, 21\%; left ventricular end-diastolic diameter (LVDd), $62 \mathrm{~mm}$; left ventricular end-systolic diameter (LVDs), $56 \mathrm{~mm}$; left atrial diameter, $51 \mathrm{~mm}$ (Fig. 3). Moderate tricuspid valve regurgitation and mild mitral valve regurgitation were observed.

After the patient was hospitalized, he was treated with oxygen inhalation and intravenous (i.v.) furosemide (40 mg). On the 3rd day of admission, i.v. furosemide was changed to an oral dose $40 \mathrm{mg}$, and enalapril $1.25 \mathrm{mg}$ was started. On the 5th day of admission, bisoprolol $0.625 \mathrm{mg}$ was added and titrated to $1.875 \mathrm{mg}$. The echocardiography performed on the 14th day demonstrated a still-low LVEF at $25 \%$, LVDd at $66 \mathrm{~mm}$, and LVDs at $58 \mathrm{~mm}$.

Coronary angiography performed on the 17th day revealed no significant coronary stenosis. The right heart

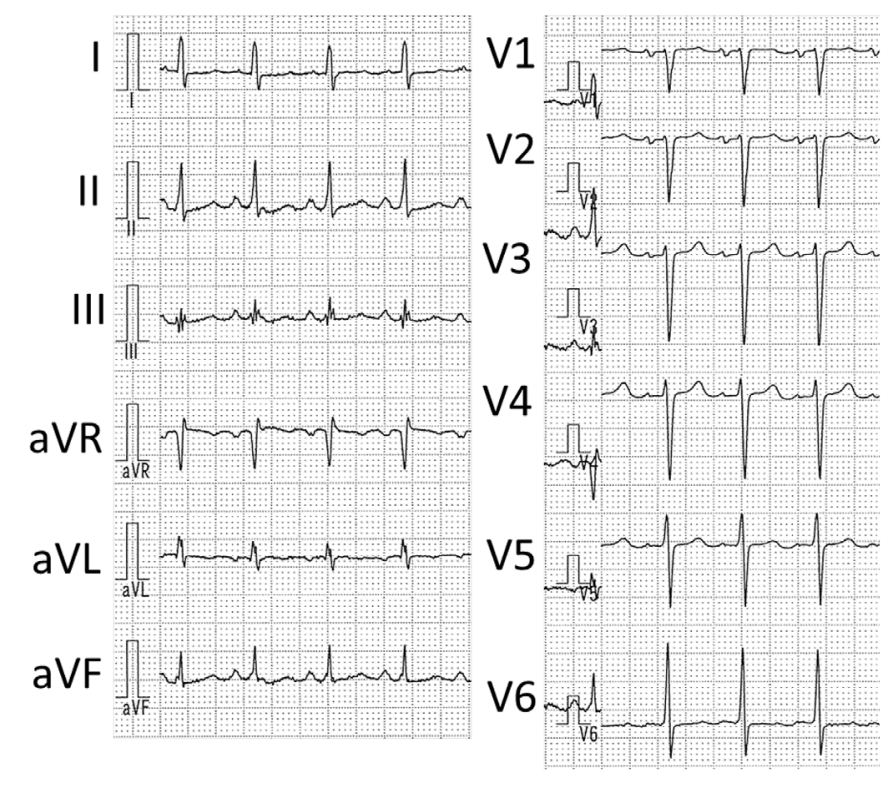

Figure 2. Twelve-lead electrocardiogram on admission demonstrated sinus tachycardia with a heart rate of $112 \mathrm{bpm}$, left atrial overload, and clockwise rotation. No ST-T wave abnormality was observed.

catheterization showed pulmonary capillary wedge pressure (PCWP), $23 \mathrm{mmHg}$; pulmonary artery systolic/diastolic/ mean pressure, 57/23/39 $\mathrm{mmHg}$; right ventricular systolic/ diastolic/mean pressure, 54/13/20 $\mathrm{mmHg}$; right atrial systolic/diastolic/mean pressure, 22/19/17 $\mathrm{mmHg}$; and cardiac index, $1.68 \mathrm{~L} / \mathrm{min} / \mathrm{m}^{2}$. An endomyocardial biopsy was performed from the right ventricle, and a histological examination showed mild myocyte hypertrophy, but no particular findings including inflammatory cell infiltration were observed (Fig. 4). According to these findings, it was considered that underlying cause of heart failure had been due to the progression of hypertensive heart disease.

On the 26th day of admission, the patient was discharged from the hospital. Because SDB was strongly suspected based on the patient's wife's report, we administered an overnight apnea test using an unattended portable sleep monitor (SAS-2100; Nihon Kohden, Tokyo, Japan). The re- 


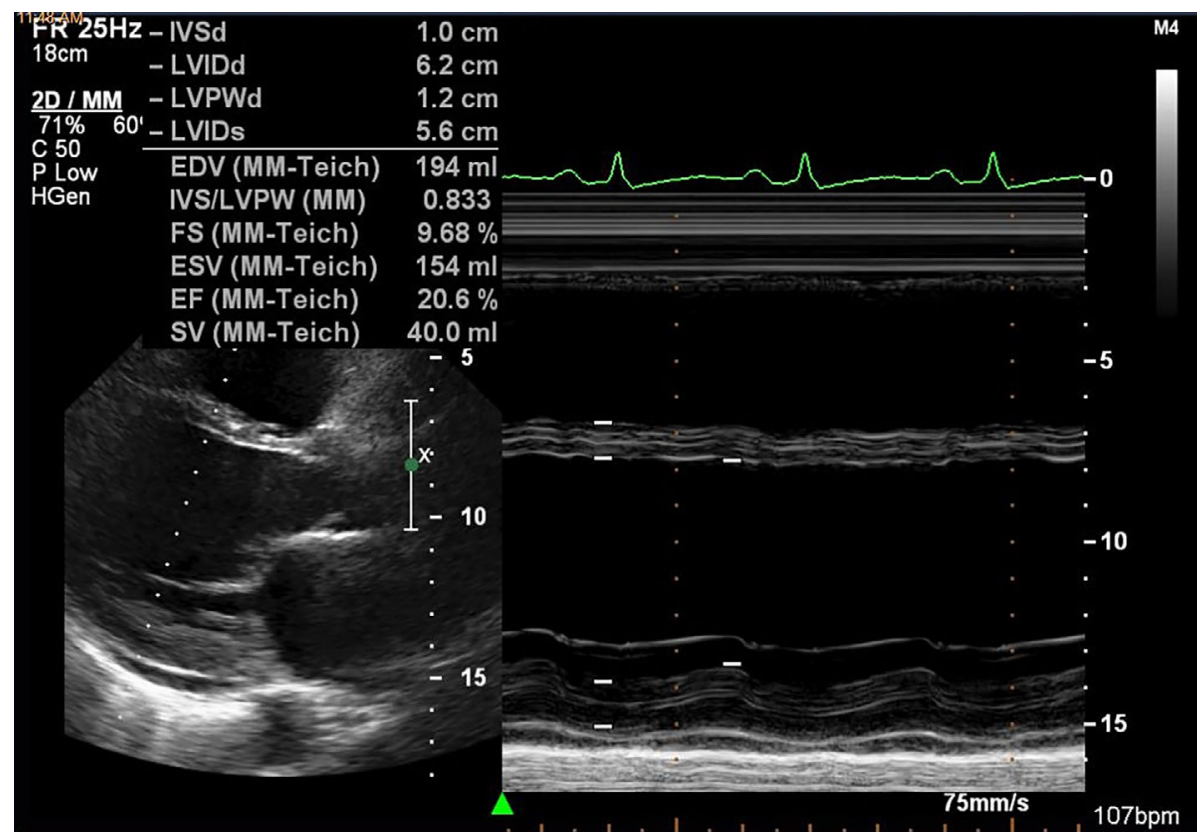

Figure 3. Echocardiography on admission showed left atrial and LV enlargement with diffuse severe hypokinesis. Moderate tricuspid valve regurgitation and mild mitral valve regurgitation were observed.

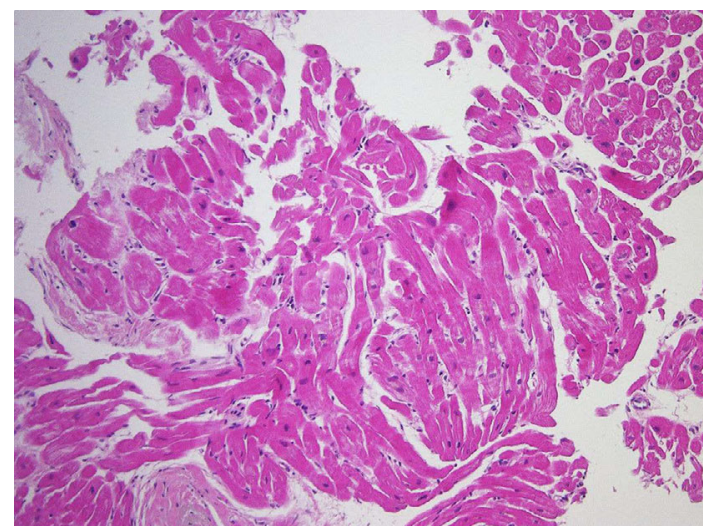

Figure 4. A histological examination showed mild myocyte hypertrophy, but there was no myocardial disorganization, fibrosis, degeneration, or inflammatory cell infiltration [Hematoxylin and Eosin staining, ×100].

sult of the test was the apnea-hypopnea index (AHI) of 41.2 per hr, $3 \%$ oxygen desaturation index of 43.5 per hr, and the lowest oxygen saturation of $64 \%$.

At 3 weeks after the patient's discharge, auto-titrating CPAP (Sleepmate S9 Auto, ResMed, San Diego, CA) was started on an outpatient basis. One month after the introduction of CPAP, the patient's LVEF had increased to $34 \%$. Seven months after the initiation of CPAP, the LVEF had increased to $50 \%$, and the LVDd and LVDs had decreased to $57 \mathrm{~mm}$ and $42 \mathrm{~mm}$, respectively (Fig. 5A). In parallel with these parameters, the brain-type natriuretic peptide (BNP) level had dropped to a normal level $(<10 \mathrm{pg} / \mathrm{mL})$ (Fig. 5B). In addition, eight months after the start of CPAP, the AHI and $3 \%$ oxygen desaturation index without using CPAP had respectively improved to 6.4 and 8.8 per hr, and the patient's body weight had fallen to $71.6 \mathrm{~kg}$.

\section{Discussion}

We treated a new-onset heart failure patient whose cardiac function dramatically improved after auto-titrating CPAP was initiated for his concurrent severe SDB. Although the standard medications for heart failure ameliorated the patient's subjective symptoms and objective congestive findings, his cardiac function had not improved until CPAP was initiated. Accordingly, we speculate that severe SDB could have had a major pathophysiological influence on the patient's heart failure and that the dramatic improvement in his cardiac function was due to the amelioration of the SDB. Because we performed the sleep apnea test using the unattended portable sleep monitor without polysomnography, the precise classification of SDB in this case is not clear, which is a major limitation associated with this case report. However, his obesity and history of snoring and apnea imply that OSA was the main pathophysiology of his SDB. In fact, the central apnea index analyzing by auto-titrating CPAP device, which was validated previously, during the beginning of treatment was very small number of 1.1 per hr (13). In addition, the restoration of upper airway obstruction through the loss of body weight may also have contributed to the improvement in our patient's cardiac function (14).

When SDB is clinically suspected in patients with heart failure, screening for SDB should be performed. In the following paragraph, we will discuss the effects of CPAP on the cardiac function by focusing on cardiac reverse remodeling and individual differences in the response to CPAP ther- 
A

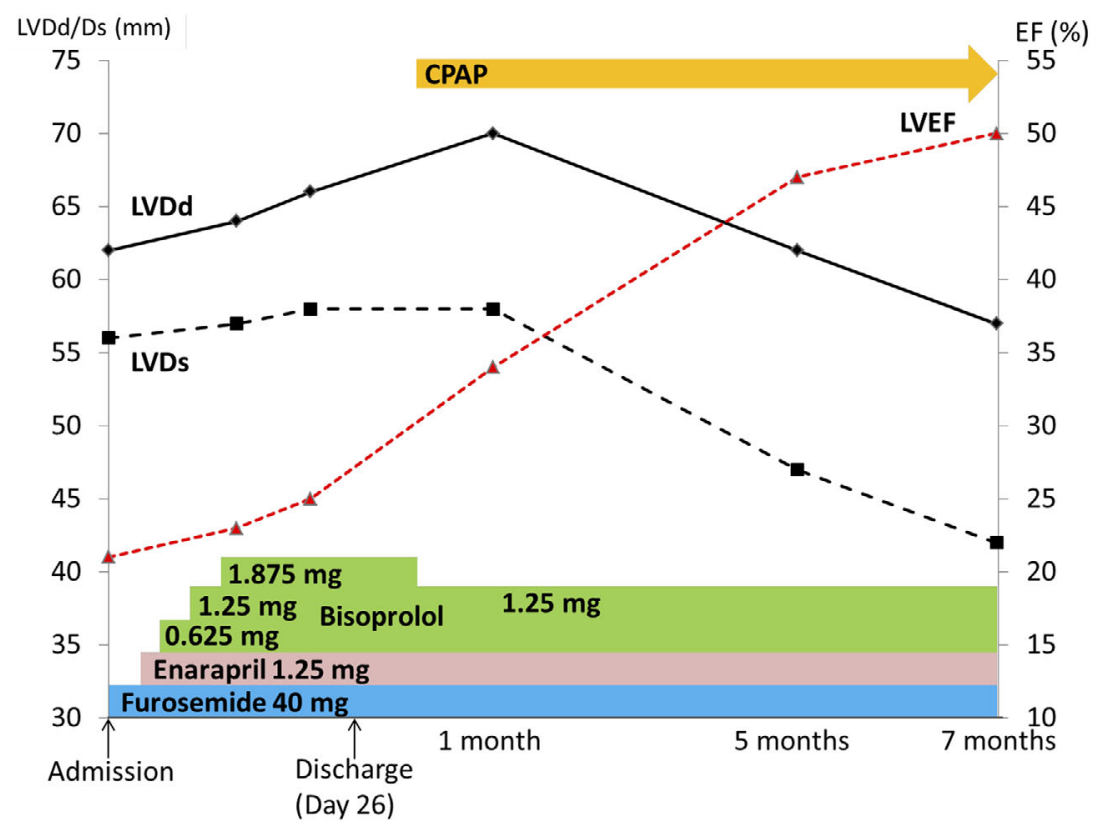

B

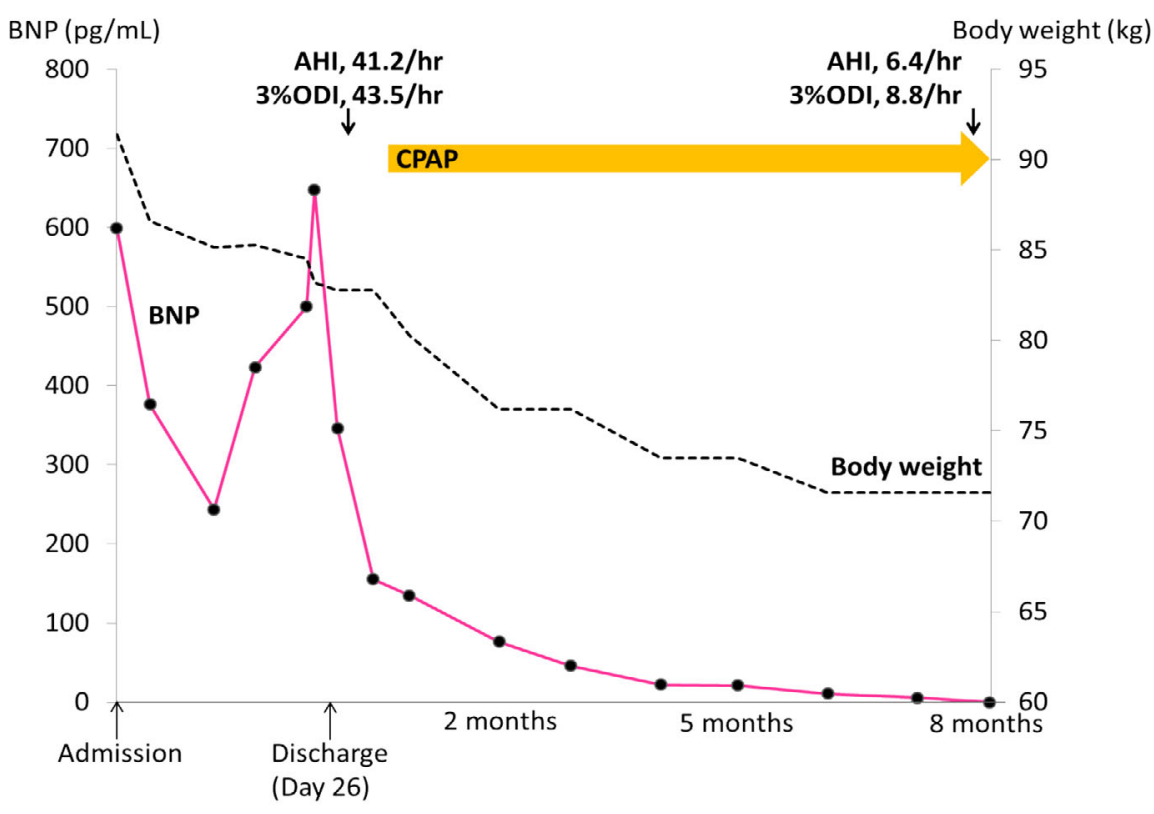

Figure 5. A: The time course of the patient's treatment and echocardiographic parameters during his admission and after discharge. After the introduction of auto-titrating CPAP, the LVDd and LVDs values markedly decreased and the EF value markedly increased. B: The time course of the BNP value and body weight during the patient's admission and after his discharge. After auto-titrating CPAP was initiated, the BNP value and body weight gradually decreased. AHI: apnea-hypopnea index, BNP: brain natriuretic peptide, CPAP: continuous positive airway pressure, EF: ejection fraction, LVDd: left ventricular end-diastolic diameter, LVDs: left ventricular end-systolic diameter, ODI: oxygen desaturation index

apy.

\section{The effects of CPAP on cardiac function in OSA pa- tients}

In the present case, dramatic reverse remodeling was observed following the introduction of CPAP therapy; the use of auto-titrating CPAP for 6 months increased the LVEF from $25 \%$ to $50 \%$ and decreased the LVDd/LVDs from 66/ $58 \mathrm{~mm}$ to $57 / 42 \mathrm{~mm}$. In previous reports, the extent of LVEF improvement by CPAP was an average of $1 \%$ to $12 \%$ in heart failure patients with OSA $(7-9,15-18)$ (Table 2). In addition, CPAP has been reported to reduce the risk of death and hospitalization in patients with heart failure and OSA $(4,19-21)$. 
Table 2. Changes in LVEF and AHI after CPAP Use in Patients with Heart Failure and Mainly OSA.

\begin{tabular}{rrcrlcrrr}
\hline & & \multicolumn{5}{c}{ Baseline characteristics } & \multicolumn{2}{c}{ Changes after CPAP use } \\
\hline Trial & $\mathrm{n}$ & $\begin{array}{l}\text { Treatment } \\
\text { duration }\end{array}$ & $\begin{array}{l}\text { Mean } \\
\text { age }\end{array}$ & $\begin{array}{l}\text { BMI } \\
\left(\mathrm{kg} / \mathrm{m}^{2}\right)\end{array}$ & $\begin{array}{l}\text { LVEF } \\
(\%)\end{array}$ & $\begin{array}{l}\text { AHI } \\
(\text { per hr })\end{array}$ & $\begin{array}{l}\text { LVEF } \\
(\%)\end{array}$ & $\begin{array}{l}\text { AHI } \\
(\text { per hr })\end{array}$ \\
\hline 15 & 8 & 4 wks. & 46.9 & 34.1 & 37 & 54.1 & 12 & -53.1 \\
7 & 12 & 1 mo. & 55.9 & 30.4 & 25.0 & 37.1 & 8.8 & -28.8 \\
8 & 19 & 3 mos. & 57.2 & 33.6 & 37.6 & 25.0 & 5.0 & -21.1 \\
16 & 26 & 6 wks. & 61 & 31 & 29 & 36 & 1 & N/A \\
9 & 19 & 6 mos. & 58.5 & 30.2 & 35.9 & 30.7 & 4.7 & -17.7 \\
17 & 28 & 3 mos. & 64 & 31.7 & 28.0 & 43 & 2.5 & -32.9 \\
18 & 12 & 1 mo. & 56.7 & 30.3 & 26.4 & 30 & 8.4 & -23 \\
\hline
\end{tabular}

AHI: apnea-hypopnea index, BMI: body mass index, CPAP: continuous positive airway pressure, CSA: central sleep apnea, LVEF: left ventricular ejection fraction, OSA: obstructive sleep apnea, SDB: sleep-disordered breathing

Cardiac reverse remodeling, an increase in LVEF and a decrease in the heart chamber size occur in diverse clinical settings, such as the use of beta blockers, an LV assist device, revascularization, and cardiac resynchronization therapy (22). However, the exact mechanism of reverse remodeling is not clear, particularly with regard to the specific molecular pathways. In patients with OSA, CPAP reduces the preload and afterload via an increase in the intrathoracic pressure (12). This leads to a decreased sympathetic nerve activity and a reduction of the myocardial oxygen demand in both the short and long term $(5,6)$. In the present case, these mechanical, neural and hemodynamic factors in addition to the administration of a beta blocker, which is the standard therapy for heart failure, may be associated with the reverse remodeling.

\section{Who benefits from CPAP therapy?}

In our patient's case, the LVEF increased from $25 \%$ to $50 \%$ after the introduction of CPAP, which is larger increase than that in previous reports $(7-9,15-18)$. However, the extent of the change in LVEF after CPAP has been reported to range from only a few percent to more than $20 \%$ among patients with heart failure and OSA (7-9).

The exact mechanism underlying the responsiveness to CPAP is not clear. Yamada et al. showed that the PCWP, pulmonary artery systolic pressure, and right atrial pressure values were significantly higher in responders than in nonresponders to positive airway pressure devices (10). It was also reported that CPAP increased the cardiac output in heart failure patients with high PCWP, and cardiac output was decreased in those with low $\operatorname{PCWP}(11,12)$. Thus, heart failure patients with high preload and low cardiac function obtained more benefits from CPAP than those with a low preload. Because our patient had a low LVEF with a high PCWP of $23 \mathrm{mmHg}$, he could be classified as a 'CPAP responder' based on the above-mentioned studies $(11,12)$.

When standard medications do not sufficiently improve a heart failure patient's cardiac function, screening for SDB should be performed. Concurrent SDB identified in heart failure patients should be treated using CPAP as recommended in the recent guidelines of the European Society of Cardiology (23). Particularly in heart failure patients with high PCWP, we strongly recommend the use of CPAP therapy.

\section{Conclusion}

We treated a patient with new-onset heart failure with SDB who achieved a dramatic improvement in his cardiac function and showed cardiac reverse remodeling by CPAP therapy in addition to standard medications. In patients with heart failure, especially in those with a high preload, CPAP therapy can be a powerful strategy to improve both cardiac function and morphology. Because patient adherence to CPAP therapy is relatively low, further investigations are needed to clarify the characteristics of heart failure patients with SDB who respond well to CPAP therapy.

The authors state that they have no Conflict of Interest (COI).

\section{References}

1. Rao A, Georgiadou P, Francis DP, et al. Sleep-disordered breathing in a general heart failure population: Relationships to neurohumoral activation and subjective symptoms. J Sleep Res 15: 81-88, 2006.

2. Javaheri S. Sleep disorders in systolic heart failure: a prospective study of 100 male patients. The final report. Int J Cardiol 106: 2128, 2006.

3. Sin DD, Fitzgerald F, Parker JD, Newton G, Floras JS, Bradley TD. Risk factors for central and obstructive sleep apnea in 450 men and women with congestive heart failure. Am J Respir Crit Care Med 160: 1101-1106, 1999.

4. Kasai T, Narui K, Dohi T, et al. Prognosis of patients with heart failure and obstructive sleep apnea treated with continuous positive airway pressure. Chest 133: 690-696, 2008.

5. Hall AB, Ziadi MC, Leech JA, et al. Effects of short-term continuous positive airway pressure on myocardial sympathetic nerve function and energetics in patients with heart failure and obstructive sleep apnea: a randomized study. Circulation 130: 892-901, 2014.

6. Kaye DM, Mansfield D, Naughton MT. Continuous positive air- 
way pressure decreases myocardial oxygen consumption in heart failure. Clin Sci 106: 599-603, 2004.

7. Kaneko Y, Floras JS, Usui K, et al. Cardiovascular effects of continuous positive airway pressure in patients with heart failure and obstructive sleep apnea. N Engl J Med 348: 1233-1241, 2003.

8. Mansfield DR, Gollogly NC, Kaye DM, Richardson M, Bergin P, Naughton MT. Controlled trial of continuous positive airway pressure in obstructive sleep apnea and heart failure. Am J Respir Crit Care Med 169: 361-366, 2004

9. Ferrier KA, Neill AM, O’Meeghan T, Richards M, Campbell AJ. Continuous positive airway pressure in heart failure patients with obstructive sleep apnoea. Intern Med J 38: 829-836, 2008.

10. Yamada S, Sakakibara M, Yokota T, et al. Acute hemodynamic effects of adaptive servo-ventilation in patients with heart failure. Circ J 77: 1214-1220, 2013.

11. Philip-Joët FF, Paganelli FF, Dutau HL, Saadjian AY. Hemodynamic effects of bilevel nasal positive airway pressure ventilation in patients with heart failure. Respiration 66: 136-143, 1999.

12. Bradley TD, Holloway RM, McLaughlin PR, et al. Cardiac output response to continuous positive airway pressure in congestive heart failure. Thorax 53: 377-382, 1992.

13. Nigro CA, Gonzalez S, Arce A, at al. Accuracy of a novel autoCPAP device to evaluate the residual apnea-hypopnea index in patients with obstructive sleep apnea. Sleep Breath 19: 569-578, 2015.

14. Peppard PE, Young T, Palta M, Dempsey J, Skatrud J. Longitudinal study of moderate weight change and sleep-disordered breathing. JAMA 284: 3015-3021, 2000.

15. Malone S, Liu PP, Holloway R, Rutherford R, Xie A, Bradley TD. Obstructive sleep apnoea in patients with dilated cardiomyopathy: effects of continuous positive airway pressure. Lancet 338: 1480-
1484, 1991.

16. Smith LA, Vennelle M, Gardner RS, et al. Auto-titrating continuous positive airway pressure therapy in patients with chronic heart failure and obstructive sleep apnoea: a randomized placebocontrolled trial. Eur Heart J 28: 1221-1227, 2007.

17. Egea CJ, Aizpuru F, Pinto JA, et al. Cardiac function after CPAP therapy in patients with chronic heart failure and sleep apnea: a multicenter study. Sleep Med 9: 660-666, 2008.

18. Gilman MP, Floras JS, Usui K, Kaneko Y, Leung RST, Bradley TD. Continuous positive airway pressure increases heart rate variability in heart failure patients with obstructive sleep apnoea. Clin Sci 114: 243-249, 2008.

19. Javaheri S, Caref EB, Chen E, Tong KB, Abraham WT. Sleep apnea testing and outcomes in a large cohort of Medicare beneficiaries with newly diagnosed heart failure. Am J Respir Crit Care Med 183: 539-546, 2011.

20. Wang H, Parker JD, Newton GE, et al. Influence of obstructive sleep apnea on mortality in patients with heart failure. J Am Coll Cardiol 49: 1625-1631, 2007.

21. Bradley TD, Floras JS. Sleep apnea and heart failure: Part I: obstructive sleep apnea. Circulation 107: 1671-1678, 2003.

22. Hellawell JL, Margulies KB. Myocardial reverse remodeling. Cardiovasc Ther 30: 172-181, 2012.

23. Ponikowski P, Voors AA, Anker SD, et al. 2016 ESC Guidelines for the diagnosis and treatment of acute and chronic heart failure. Eur J Heart Fail 18: 891-975, 2016.

The Internal Medicine is an Open Access article distributed under the Creative Commons Attribution-NonCommercial-NoDerivatives 4.0 International License. To view the details of this license, please visit (https://creativecommons.org/licenses/ by-nc-nd/4.0/).

(C) 2017 The Japanese Society of Internal Medicine Intern Med 56: 2289-2294, 2017 